\title{
Texture Evolution, Formability and Ridging Resistance of a Sn-bearing Ferritic Stainless Steel Under Different Hot Band Annealing Temperatures
}

\author{
Yang Bai ${ }^{1} \cdot$ Tong He$^{2} \cdot$ Dan Guo ${ }^{1} \cdot$ Xiu-Ting Liu ${ }^{1}$. Fang-Yuan Shao ${ }^{1} \cdot$ Yan-Dong Liu ${ }^{1}$ \\ Received: 26 December 2018 / Revised: 4 March 2019 / Published online: 30 March 2019 \\ (C) The Chinese Society for Metals (CSM) and Springer-Verlag GmbH Germany, part of Springer Nature 2019
}

\begin{abstract}
The microstructure, texture evolution and spatial orientation distribution during cold rolling and the subsequent annealing as well as formability and ridging of a Sn-bearing ferritic stainless steel under different hot band annealing temperatures were investigated. The four hot bands with annealing temperatures of $900,950,1000$ and $1050^{\circ} \mathrm{C}$ were all cold-rolled to $80 \%$ reductions and then were annealed at the same temperature of $900{ }^{\circ} \mathrm{C}$. The results show that optimizing hot band annealing process is beneficial to reduce the amount of $\{001\}<110>$ grains and weaken the texture intensity, and thus, to reduce ridging and improve formability. In the present study, the final sheets with hot band annealing temperature of $900{ }^{\circ} \mathrm{C}$ possess small and inhomogeneous grains with a large amount of $\{001\}<110>$ orientations, which deteriorates the formability and increases the ridging. In comparison, the final sheets with hot band annealing temperature of $950{ }^{\circ} \mathrm{C}$ are comprised of uniform and equiaxed $<111>/$ /ND (ND: normal direction) recrystallized grains with a high texture intensity favorable for the improvement in $r$ value and surface quality. However, when hot band annealing temperature further increases to 1000 and $1050{ }^{\circ} \mathrm{C}$, it shows a sharp decrease in $r$ value and a remarkable increase in ridging as a result of a reduction in $\gamma$-fiber texture intensity and an increase in grain size in the final sheets. Suitable controlling and optimizing hot band annealing process is essential to improve the formability and reduce the ridging.
\end{abstract}

Keywords Ferritic stainless steel $\cdot$ Texture $\cdot$ Formability $\cdot$ Ridging

\section{Introduction}

Sn-bearing ferritic stainless steel (FSS) is a newly developed resource-saving stainless steel which could save the cost greatly and become a substitute for some austenitic stainless steels (ASSs) [1, 2]. In recent years, Sn micro-alloying has been popular in optimizing various performances of FSSs [3-5]. A number of researchers have confirmed that Sn microalloying in the steel could improve the corrosion resistance in acid or neutral solution $[6,7]$. However, the newly developed

Available online at http://link.springer.com/journal/40195

Yan-Dong Liu

ydliu@mail.neu.edu.cn

$1 \quad$ Key Laboratory for Anisotropy and Texture of Materials of Ministry of Education, Northeastern University, Shenyang 110819, China

2 Research Academy, Northeastern University, Shenyang 110819, China
Sn-bearing FSS has a lower formability in comparison with ASS, which limits its application in more areas.

Controlling crystallographic texture and microstructure is an effective method to optimize the formability of ferritic stainless steel. In general, the formability of FSS can be improved by increasing the plastic strain ratio ( $r$ value) which closely related with the $\gamma$-fiber recrystallization texture and the uniform grain size distribution. Hamada et al. [8] investigated the effect of texture on $r$ value of ferritic stainless steel sheets, and they found that the formability could be improved by increasing the $r$ value which was closely related with $\gamma$-fiber $(<111>/ / \mathrm{ND}$; ND: normal direction) recrystallization texture. Shu et al. [9] pointed out that $\mathrm{Nb}+\mathrm{Ti}$ dual stabilization $15 \% \mathrm{Cr}$ ferritic stainless steel obtained higher average $r$ value and lower planer anisotropy which was attributed to the high intensity and uniform $\gamma$-fiber texture. Yan et al. [10] proposed that the uniform grain size distribution is beneficial for the formation of uniform and sharp $\gamma$-fiber recrystallization texture and improves the formability of ferritic stainless steel. The texture in FSS is largely affected by thermomechanical process. The hot band usually displays 
pronounced $\{001\} / / N D$ texture, which will control the texture evolution and the formability during the whole manufacturing process [11]. It should also be mentioned that the $\{001\}$ $<110>$ orientations show a low plastic resistance, which leads to a remarkable increase in ridging and affects the surface gloss of steel sheets [12]. The hot band annealing could reduce the texture sharpness and affect the subsequent cold rolling and the final recrystallization textures significantly which improves formability and reduces ridging of ferritic stainless steels [13]. Hence, the introduction of hot band annealing between hot rolling and cold rolling is essential.

So far, most of the researches are focused on the comparison of texture, microstructure and formability of FSSs between with and without hot band annealing treatment, and it is confirmed that the formability of FSSs could be improved by the hot band annealing treatment [13-15]. However, whether the formability of the newly developed Sn-bearing FSS could be improved by hot band annealing is not clear. Moreover, for the Sn-bearing ferritic stainless steel, no research has been performed to study the effect of hot band annealing process on the microstructure and texture evolution during cold rolling and subsequent recrystallization annealing and its properties. The further optimization of hot band annealing process to improve the formability and ridging resistance of $\mathrm{Sn}$-bearing ferritic stainless steel has become an urgently problem, which needs studying.

In our present study, the four hot bands with annealing temperatures of $900,950,1000$ and $1050{ }^{\circ} \mathrm{C}$ were all cold-rolled to $80 \%$ reductions followed by annealing at the same temperature of $900{ }^{\circ} \mathrm{C}$. The microstructure and texture evolution as well as formability and ridging of Sn-bearing ferrite stainless steel under different hot band annealing (HBA) temperatures were studied. The aim is to explore the effect of HBA temperature on the microstructure and texture evolution, formability and surface ridging of a Sn-bearing ferritic stainless steel, and to develop the Sn-bearing ferritic stainless steel with excellent formability and ridging resistance through the optimization of process parameters.

\section{Experimental}

\subsection{Materials and Preparation}

The chemical composition of a Sn-bearing ferritic stainless steel is given in Table 1. In our experiment, the ingots were melted and casted under a high vacuum and then were forged into a rectangle shape. The slabs with $300 \mathrm{~mm}$ in length,
$70 \mathrm{~mm}$ in width and $70 \mathrm{~mm}$ in thickness were cut from the ingots. These slabs were rough rolled at 1050 to $1000{ }^{\circ} \mathrm{C}$ and then finished rolled at $800^{\circ} \mathrm{C}$, and the hot bands were rolled by ten passes to a thickness of $5.0 \mathrm{~mm}$. Subsequently, the hot bands were annealed at $900,950,1000$ and $1050{ }^{\circ} \mathrm{C}$ for $5 \mathrm{~min}$, respectively. All the hot-rolled and annealed bands were then cold-rolled with a reduction of $80 \%$ to a final thickness of $1 \mathrm{~mm}$ and subsequently were all annealed at $900{ }^{\circ} \mathrm{C}$ for $2 \mathrm{~min}$.

\subsection{Microstructure Observation}

The samples for microstructure observation were made by grinding on emery paper and then were etched in a solution of $5 \mathrm{~g} \mathrm{CuSO}_{4}, 20 \mathrm{~mL} \mathrm{H}_{2} \mathrm{O}$ and $20 \mathrm{~mL} \mathrm{HCl}$. The microstructure observation was performed by OLYMPUS GX71 optical microscope, and the grain size was determined by a linear intercept method.

\subsection{XRD Measurement}

The specimens for X-ray diffraction (XRD) measurement were processed by mechanical grinding and polishing followed by etching in dilute hydrochloric acid $(\mathrm{HCl})$. The XRD measurement was taken by X' Pert PRO X-ray diffractometer with $\mathrm{Co} K_{\alpha}$ radiation to determine the texture, and the location of the measurement for XRD analysis is at the center layer of the specimens. The orientation distribution functions (ODFs) were calculated from 3 incomplete pole figures $\{110\},\{200\}$ and $\{211\}$ according to Bunge by series expansion method [16].

\subsection{EBSD Measurement}

The specimens for electron backscattering diffraction (EBSD) measurement were made by electrolytic polishing in $12.5 \mathrm{~mL}$ $\mathrm{HClO}_{4}, 35 \mathrm{~mL} \mathrm{H}_{2} \mathrm{O}$ and $187.5 \mathrm{~mL} \mathrm{C}_{2} \mathrm{H}_{5} \mathrm{OH}$. The EBSD measurement was taken by JEOL JSM 7001F scanning electron microscopy (SEM) with an EBSD detector to determine the samples' crystal orientation maps. In terms of the cold-rolled sheet, it was determined with a magnification of 1000 and a step size of $0.2 \mu \mathrm{m}$; in the case of the final cold-rolled and annealed sheets, it was measured with a magnification of 200 and a step size of $1 \mu \mathrm{m}$.

\subsection{Average Normal Anisotropy Coefficient}

Tensile test was employed to measure the average $r$ value and $\Delta r$ value of the experimental steel so as to evaluate the
Table 1 Chemical compositions of Sn-bearing ferritic stainless steel (wt $\%)$

\begin{tabular}{lllllllllll}
\hline $\mathrm{C}$ & $\mathrm{S}$ & $\mathrm{N}$ & $\mathrm{Mn}$ & $\mathrm{P}$ & $\mathrm{Al}$ & $\mathrm{Cr}$ & $\mathrm{Nb}$ & $\mathrm{Ti}$ & $\mathrm{Sn}$ & $\mathrm{Fe}$ \\
\hline 0.01 & 0.003 & 0.012 & 0.21 & 0.005 & 0.035 & 16.5 & 0.15 & 0.15 & 0.3 & Bal. \\
\hline
\end{tabular}


influence of HBA temperature on the formability of the experimental steel. In the experiment, the average $r$ value and $\Delta r$ value were calculated using the following equations [11]:

$\bar{r}=\frac{r_{0^{\circ}}+r_{45^{\circ}}+r_{90^{\circ}}}{4}$,

$\Delta r=\frac{r_{0^{\circ}}+r_{45^{\circ}}}{2}-r_{90^{\circ}}$.

\subsection{Ridging Measurement}

Ridging was determined along the TD (transverse direction) on the surfaces of tensile samples strained by $15 \%$ parallel to the RD (rolling direction) by a profilometer, and the surface roughness profile was obtained. In our study, the difference in height between the peak and the valley of the surface roughness profile is defined as ridging height.

\section{Results and Discussion}

\subsection{Microstructure Evolution}

Figure 1 presents the microstructure of hot bands for the Sn-bearing ferritic stainless steel. As shown in the microphotograph, the microstructure of the hot bands is comprised of elongated ferritic grains parallel to the rolling direction, and the interior of hot bands is very smooth.

Figure 2 presents the microstructures of hot bands after annealing at different temperatures. When the temperature is $900{ }^{\circ} \mathrm{C}$, small and inhomogeneous grains are presented in the annealed bands, and the mean grain size is $38.5 \mu \mathrm{m}$. When the temperature is $950{ }^{\circ} \mathrm{C}$, uniform and equiaxed grains are shown in the annealed bands, and the mean grain size is $45.8 \mu \mathrm{m}$. When the temperature increases to $1000^{\circ} \mathrm{C}$, the grain size further increases with the rising temperature with a mean grain size of $56.3 \mu \mathrm{m}$. When it rises to $1050{ }^{\circ} \mathrm{C}$, non-uniform grains are presented in the annealed bands, accompanying with the occurrence of large-size grains (larger than $100 \mu \mathrm{m}$ ) in some grains, and the mean grain size reaches $68.6 \mu \mathrm{m}$. In conclusion, with the increase in annealing temperature, small grains are gradually swallowed into the adjacent large grains accompanying with the migration of grain boundaries, and the grain sizes of the hot band annealed specimens are increased significantly.

Figure 3 shows the cold rolling microstructures of the Sn-bearing ferritic stainless steel with different hot band annealing (HBA) temperatures. When the HBA temperature is $900{ }^{\circ} \mathrm{C}$, the deformation band in the cold-rolled sheets is narrow with numerous grain boundaries due to the small-size grains in the hot band annealed specimens. When the HBA temperature is $950{ }^{\circ} \mathrm{C}$, the width of the deformation band

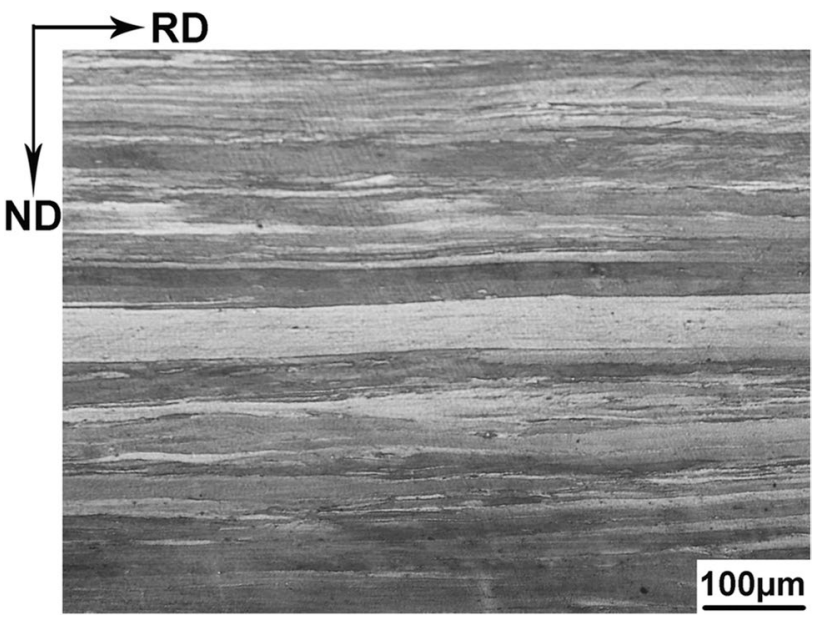

Fig. 1 Microstructure of hot bands

increases; meanwhile, it can be clearly seen that the shear bands are formed in the deformed grains which incline to the rolling direction by $30^{\circ}-45^{\circ}$. In terms of the cold-rolled sheets with the HBA temperature of $1000{ }^{\circ} \mathrm{C}$, the width of deformation band further increases with increasing grain size in hot band annealed specimens. In the case of the cold-rolled sheets with HBA temperature of $1050{ }^{\circ} \mathrm{C}$, the shear bands existed in some deformation bands are more clearly visible. On the other hand, the non-uniform and coarse deformation microstructure appears in the cold-rolled sheets, resulting from the inhomogeneous grains and the significant grain growth in the hot band annealed samples. In conclusion, the deformation bands in the cold-rolled sheets are gradually widened and the number of grain boundaries is gradually decreased when the HBA temperature rises from 900 to $1050{ }^{\circ} \mathrm{C}$.

Figure 4 shows the microstructures of final sheets with different HBA temperatures. It is shown that the all the coldrolled sheets with different hot band annealing temperatures have been completely recrystallized after annealing and the deformed ferrites have been replaced by recrystallization grains. When HBA temperature is $900{ }^{\circ} \mathrm{C}$, small and inhomogeneous grains are presented in the final sheets, and the mean grain size is $10.8 \mu \mathrm{m}$. By comparison, more uniform and equiaxed recrystallization grains are obtained in the final sheets with HBA temperature of $950{ }^{\circ} \mathrm{C}$, and the grain size is also greater with the average size of $18.7 \mu \mathrm{m}$. When HBA temperature is $1000{ }^{\circ} \mathrm{C}$, the recrystallization grain size of the final sheets further increases, and the mean grain size is $26.7 \mu \mathrm{m}$. When HBA temperature increases to $1050^{\circ} \mathrm{C}$, the recrystallization grain size of the final sheets increases significantly, and the average grain size is $34.5 \mu \mathrm{m}$. Moreover, the recrystallized grains are distributed inhomogeneously accompanying with the appearance of large-size recrystallization grains. The recrystallization grain size of the final sheets is closely related to the cold rolling microstructure. 

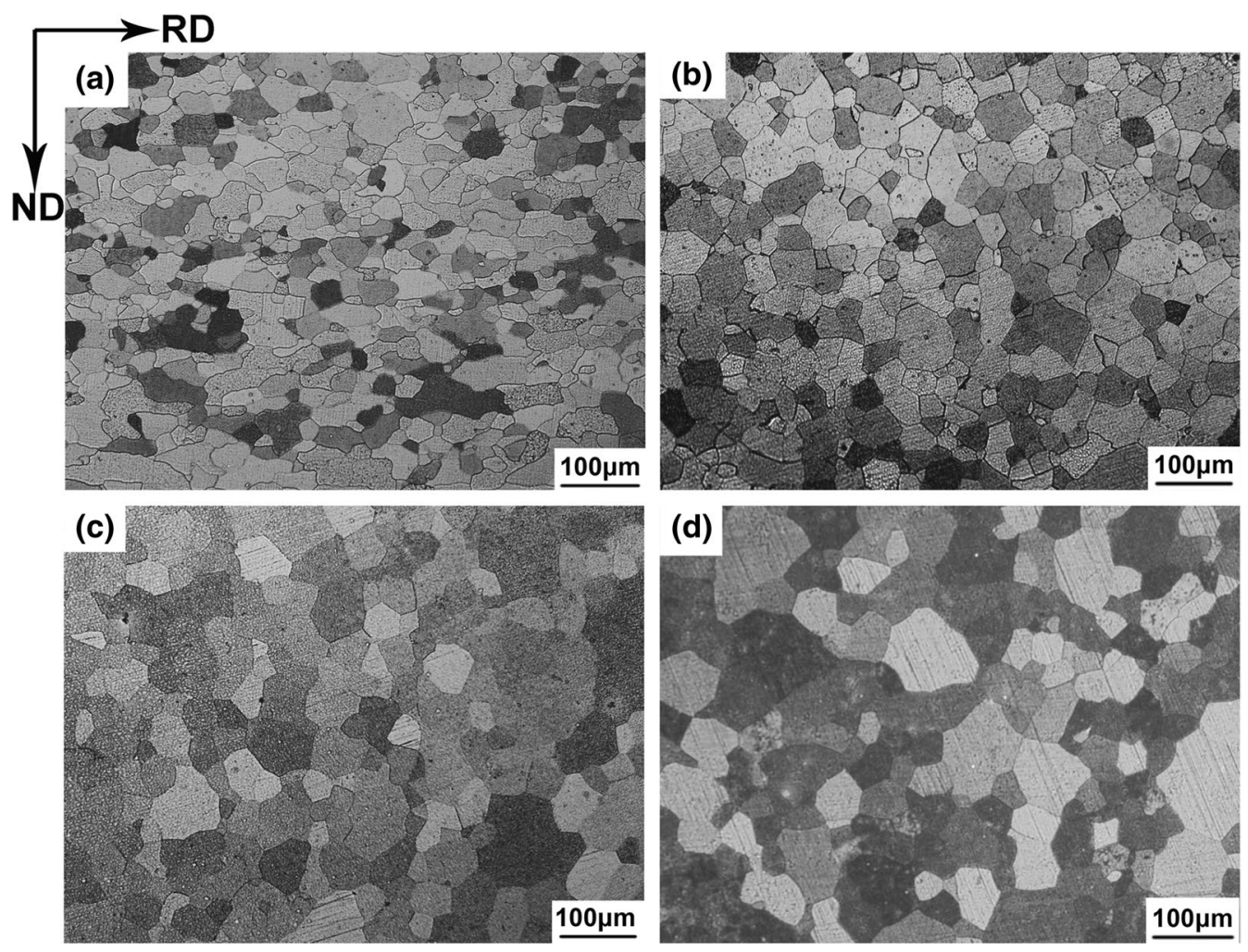

Fig. 2 Microstructures of hot bands after annealing at different temperatures: a $900{ }^{\circ} \mathrm{C} ; \mathbf{b} 950{ }^{\circ} \mathrm{C} ; \mathbf{c} 1000{ }^{\circ} \mathrm{C} ; \mathbf{d} 1050{ }^{\circ} \mathrm{C}$
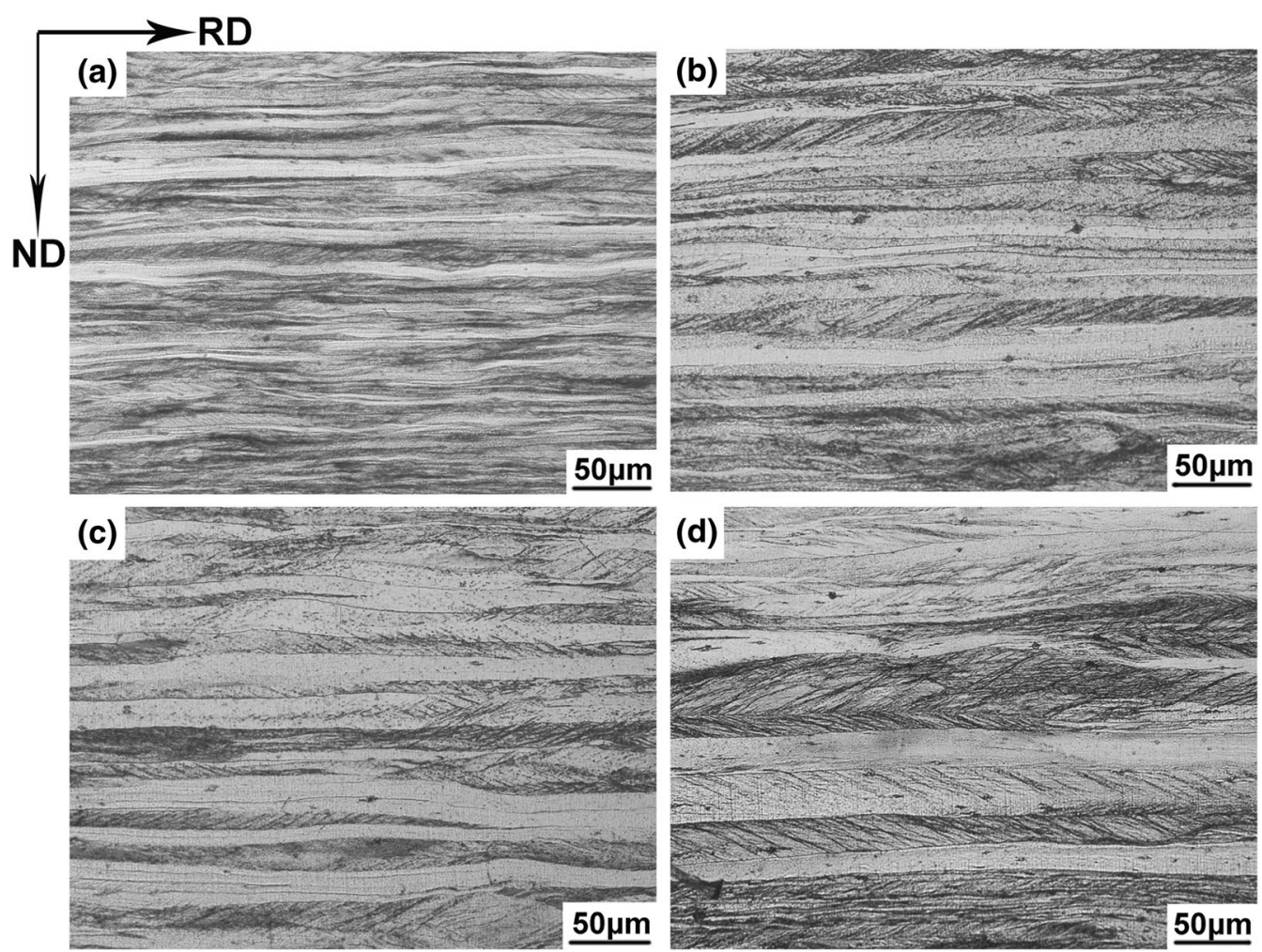

Fig. 3 Microstructures of cold-rolled sheets with different hot band annealing temperatures: a $900{ }^{\circ} \mathrm{C} ; \mathbf{b} 950{ }^{\circ} \mathrm{C} ; \mathbf{c} 1000{ }^{\circ} \mathrm{C} ; \mathbf{d ~} 1050{ }^{\circ} \mathrm{C}$ 

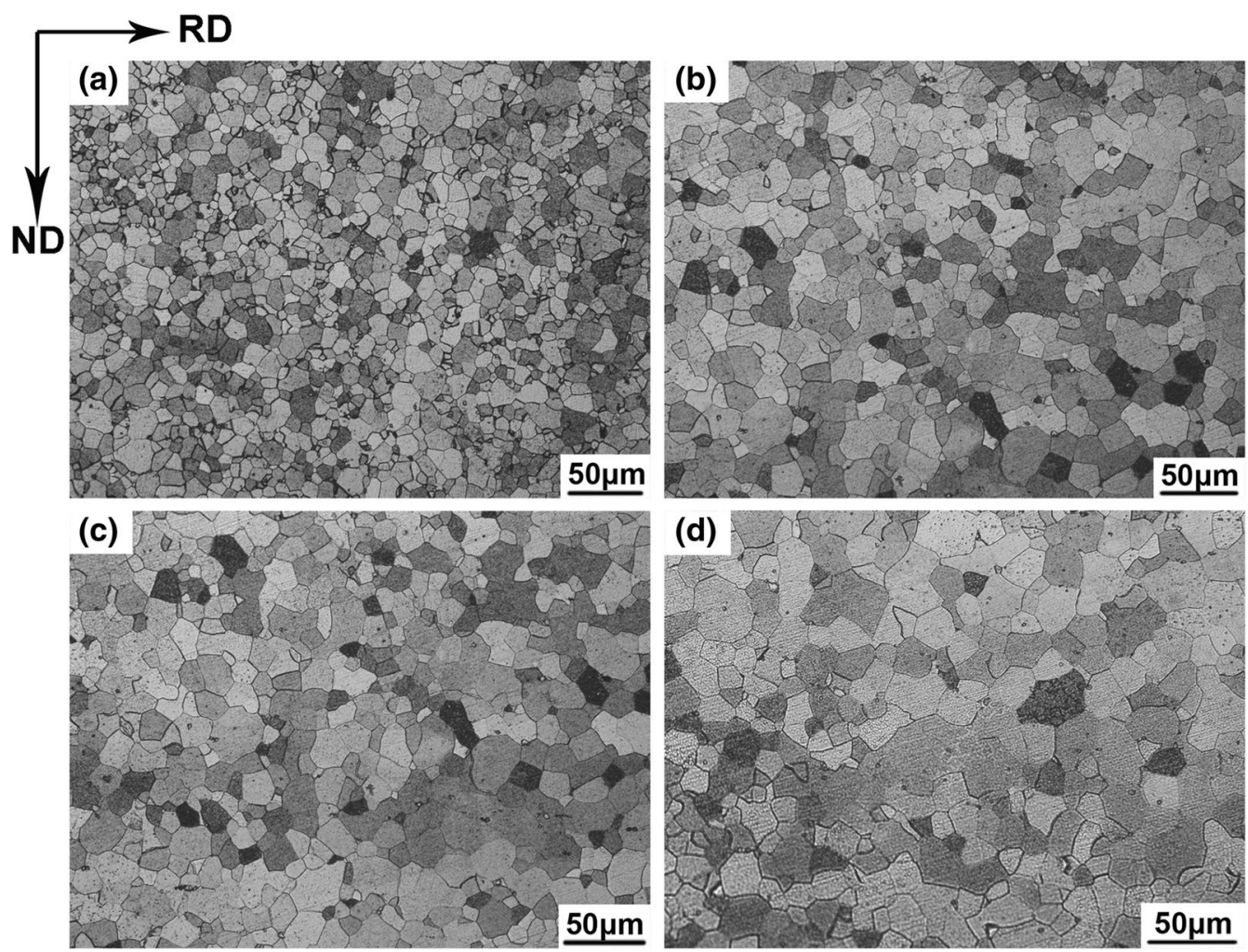

Fig. 4 Microstructure of final sheets with different hot band annealing temperatures: a $900{ }^{\circ} \mathrm{C} ; \mathbf{b} 950{ }^{\circ} \mathrm{C} ; \mathbf{c} 1000{ }^{\circ} \mathrm{C} ; \mathbf{d ~} 1050{ }^{\circ} \mathrm{C}$

As is noted earlier, with the increase in HBA temperature, it shows a significant increase in the grain size in the hot band annealed samples, and the width of deformation band is increased and the number of grain boundaries is reduced in the cold-rolled sheets, which will result in a reduction in the nucleation positions for recrystallization grains; hence, the number of recrystallization grains is decreased and the grain size is increased.

\subsection{Texture Evolution}

Ferritic stainless steels are prone to form two typical fiber textures during rolling and annealing: the $\alpha$-fiber texture with a $<110>$ crystal orientation parallel to RD and the $\gamma$-fiber texture with $\{111\}$ plane parallel to rolling plane [17, 18]. These typical orientations can all be shown in $\varphi_{2}=45^{\circ}$ sections of ODFs; hence, the $\varphi_{2}=45^{\circ}$ ODFs is selected to investigate the texture evolutions in the present work.

Figure 5 shows the ODFs ( $\varphi_{2}=45^{\circ}$ sections) of the center layer of the hot bands. It is evident that the hot rolling texture of Sn-bearing ferritic stainless steel is composed of a strong $\alpha$-fiber texture and a weak $\gamma$-fiber texture. The strongest $\alpha$-fiber texture is located at $\{001\}<110>$, and the strongest $\gamma$-fiber texture is located at $\{111\}<110>$. Ferritic stainless steel is difficult to be recrystallized during hot rolling due to the rapid dynamic recovery. In terms of the major $\alpha$-fiber texture component $\{001\}<110>$, the recrystallization rate is quite low because of its low stored energy [19]. Hence, the hot band shows a strong $\alpha$-fiber texture.

Figure 6 shows the ODFs ( $\varphi_{2}=45^{\circ}$ sections $)$ of the center layer of the hot bands after annealing at different temperatures. The texture of hot bands after annealing at the temperature range of $900-1050{ }^{\circ} \mathrm{C}$ all consists of strong $\alpha$-fiber textures and weak $\gamma$-fiber textures. The

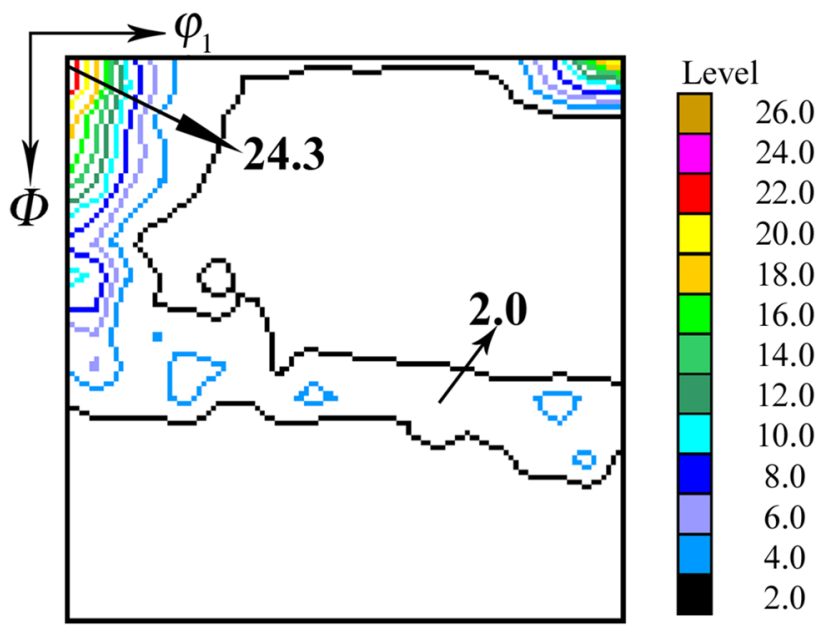

Fig. 5 Orientation distribution functions (ODFs) $\left(\varphi_{2}=45^{\circ}\right.$ sections) of center layer of hot bands $\left(\varphi_{1}, \varphi_{2}, \Phi\right.$ : Euler angles) 
strongest $\alpha$-fiber textures are all concentrated in $\{114\}$ $<110>$, and the strongest $\gamma$-fiber textures are all focused on $\{111\}<112>$. In addition, compared with the texture in hot bands, the $\alpha$-fiber texture intensity is sharply decreased in the annealed samples, especially for the $\{001\}<110>$ component. Moreover, when the temperature rises from 900 to $1050{ }^{\circ} \mathrm{C}$, the $\alpha$-fiber texture is significantly weakened and the $\gamma$-fiber texture is slightly enhanced. The reason why the $\alpha$-fiber texture is significantly weakened and $\gamma$-fiber texture is slightly enhanced after annealing can be explained as follows. During the hot band annealing, the high annealing temperature reduces the time for recovery and promotes recrystallization, which results in a reduction in $\alpha$-fiber texture and the enhancement of $\gamma$-fiber texture [15]. In addition, the $\{001\}<110>$ grains which are the major texture components in the hot band possess a low recrystallization rate, and they will be separated and swallowed by the growth of other oriented grains around them during the annealing. The $\{111\}\langle u v w\rangle$ grains possess the high grainboundary energy, and they will grow gradually with the rising annealing temperature. Hence, the $\alpha$-fiber is greatly weakened and $\gamma$-fiber texture is slightly enhanced with the rising temperature.

Figure 7 shows the ODFs ( $\varphi_{2}=45^{\circ}$ sections) of the center layer of the cold-rolled sheets with different HBA temperatures. The cold rolling textures of Sn-bearing ferritic stainless steel are all composed of strong $\alpha$-fiber textures and

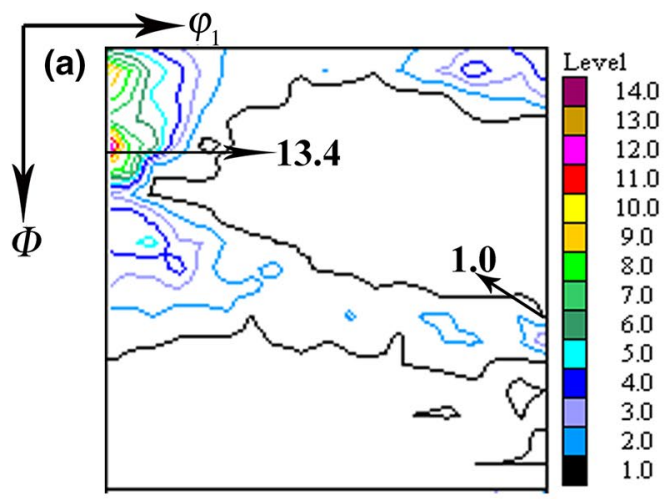

(c)

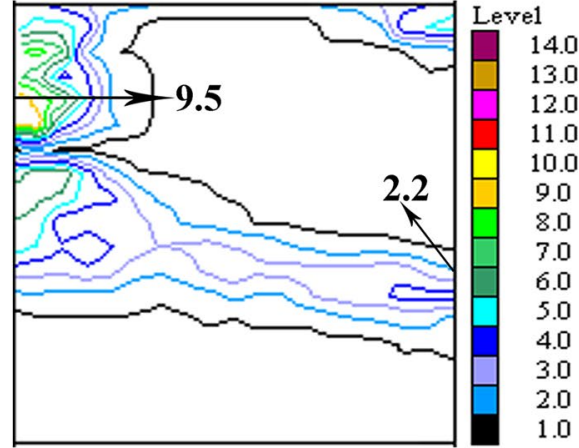

weak $\gamma$-fiber textures under different HBA temperatures. In terms of the cold-rolled sheets with HBA temperature that ranges from 900 to $1000{ }^{\circ} \mathrm{C}$, the $\alpha$-fiber texture shows a maximum at $\{112\}<110\rangle$, and the $\gamma$-fiber texture presents a maximum at $\{111\}<110>$. In the case of the cold-rolled sheets with HBA temperature of $1050{ }^{\circ} \mathrm{C}$, the $\alpha$-fiber texture shows a peak at $\{223\}<110>$, while the $\gamma$-fiber texture remains a peak at $\{111\}<110>$. On the other hand, for the cold-rolled sheets with HBA temperature range from 900 to $1050{ }^{\circ} \mathrm{C}$, it is evident that the orientation density of $\alpha$-fiber texture gradually decreases, while the orientation density of $\gamma$-fiber texture gradually increases with the rising HBA temperature. In conclusion, when the HBA temperature increases from 900 to $1050{ }^{\circ} \mathrm{C}$, the strongest $\alpha$-fiber texture transfers from $\{112\}<110>$ to $\{223\}<110>$, and the strongest $\gamma$-fiber texture remains at $\{111\}<110>$ in coldrolled sheets. In addition, $\alpha$-fiber texture is weakened and $\gamma$-fiber texture is enhanced in cold-rolled sheets.

Figure 8 shows the crystal orientation maps of the center region of the cold-rolled sheets with different HBA temperatures. The crystal orientation maps present the crystal orientations parallel to ND. The red represents $<001>/$ /ND grains and the blue stands for $<111>/ / \mathrm{ND}$ grains, as indicated in the stereo triangle. The cold rolling microstructure consists of the elongated ferritic grains parallel to the RD. Moreover, with the increase in HBA temperature, the cold-rolled deformation bands are gradually widened and the number of grain boundaries is gradually reduced. In terms of the spatial

(b)
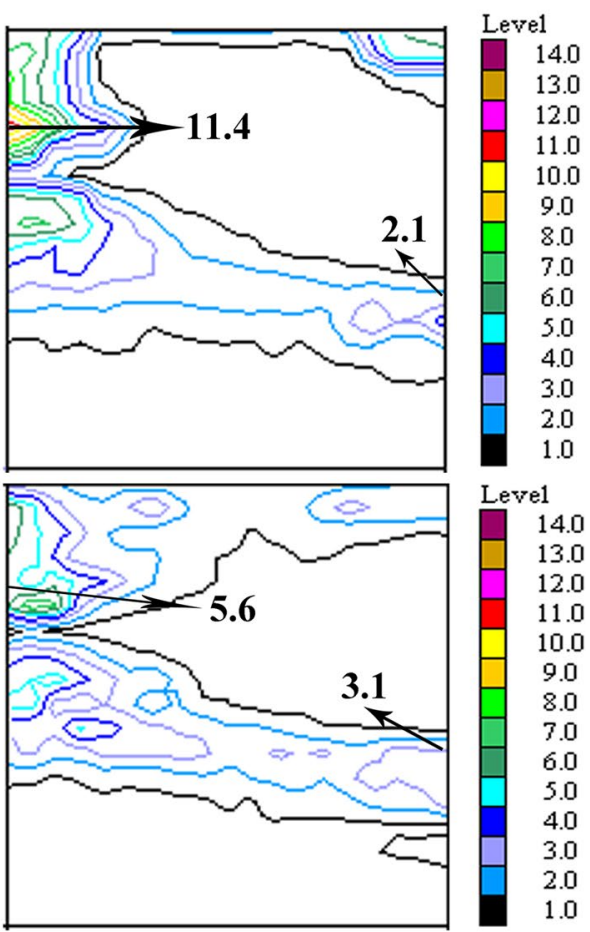

Fig. 6 ODFs $\left(\varphi_{2}=45^{\circ}\right.$ sections) of center layer of hot bands annealing at different temperatures: a $900{ }^{\circ} \mathrm{C} ; \mathbf{b} 950{ }^{\circ} \mathrm{C} ; \mathbf{c} 1000{ }^{\circ} \mathrm{C} ; \mathbf{d} 1050{ }^{\circ} \mathrm{C}$ 


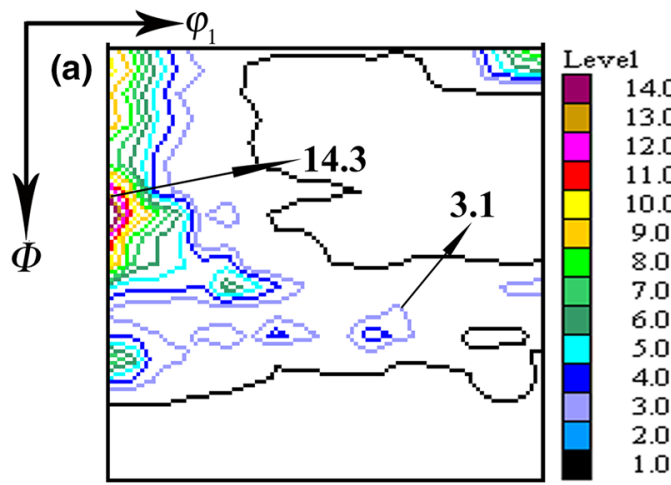

(c)

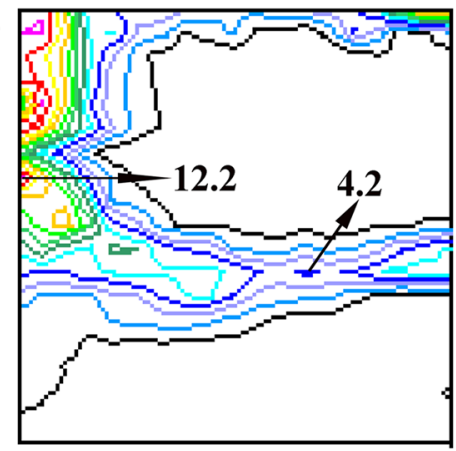

(b)

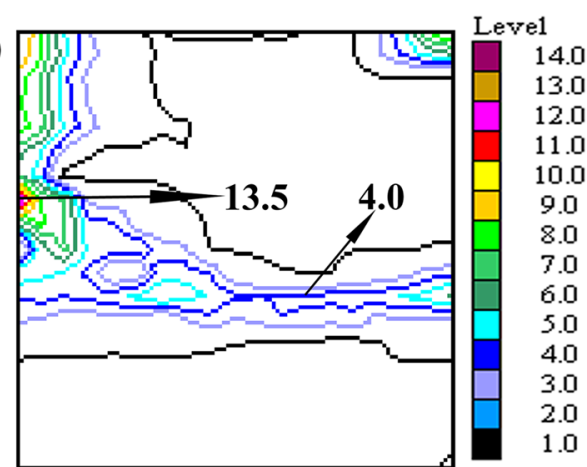

(d)

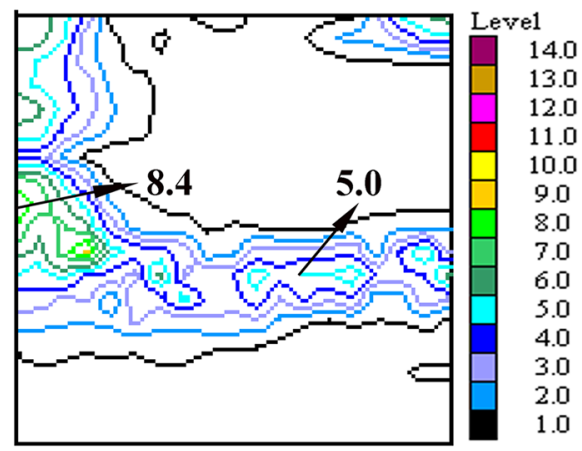

Fig. 7 ODFs $\left(\varphi_{2}=45^{\circ}\right.$ sections $)$ of center layer of cold-rolled sheets with different hot band annealing temperatures: a $900{ }^{\circ} \mathrm{C}$; b $950{ }^{\circ} \mathrm{C}$; c $1000{ }^{\circ} \mathrm{C} ; \mathbf{d} 1050{ }^{\circ} \mathrm{C}$
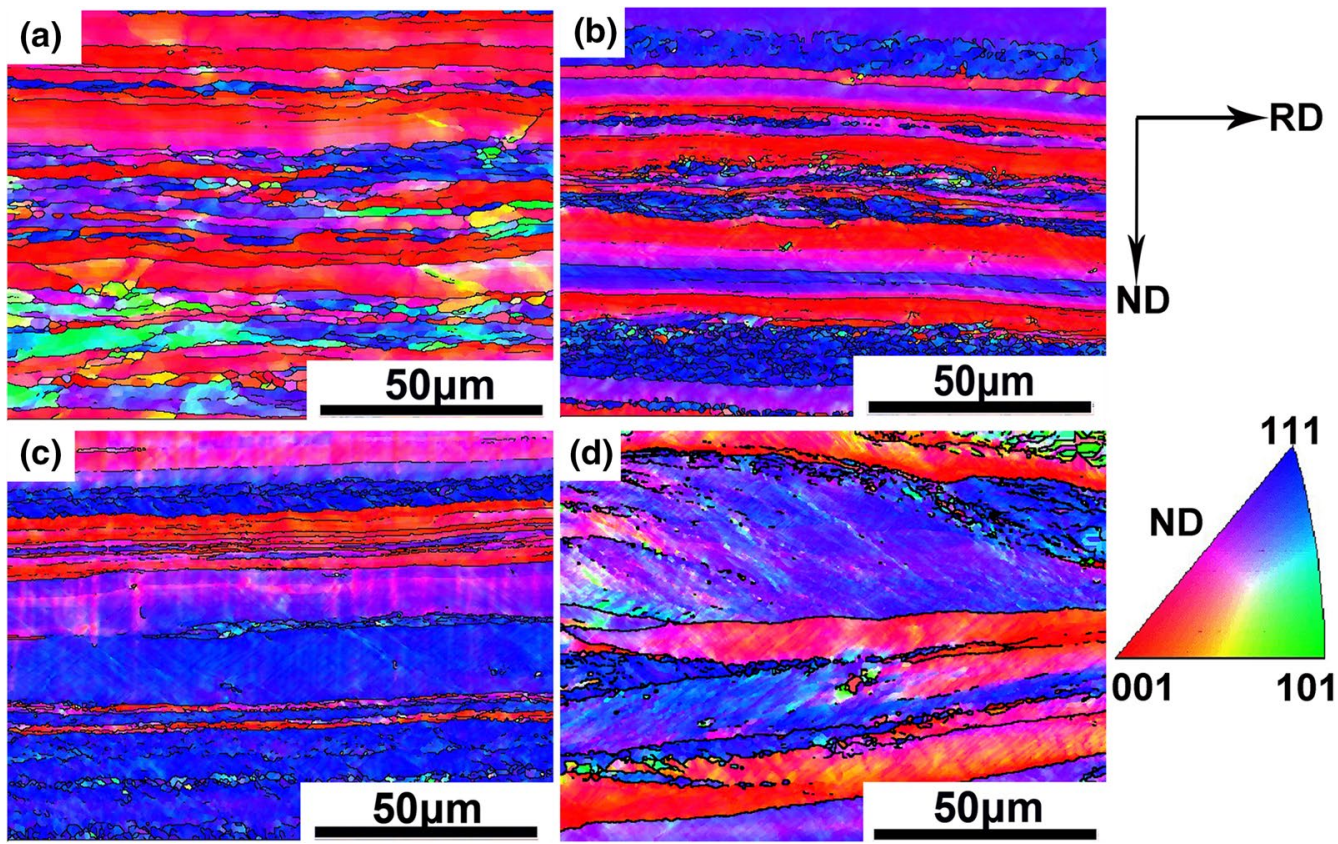

Fig. 8 Crystal orientation maps of central region of cold-rolled sheets with different hot band annealing temperatures: a $900{ }^{\circ} \mathrm{C}$; b $950{ }^{\circ} \mathrm{C}$; c $1000{ }^{\circ} \mathrm{C} ; \mathbf{d} 1050{ }^{\circ} \mathrm{C}$

distribution of grain orientations, overall, the $<001>$ //ND grains in cold-rolled sheets are reduced and the $<111>$ // ND grains are increased with the rising HBA temperature. Hence, the increasing HBA temperature results in a decrease in the $<001>/ / \mathrm{ND}$ grains and an increase in $<111>/ / \mathrm{ND}$ grains in cold-rolled sheets. This is in accordance with macro-texture result that $\alpha$-fiber texture is weakened and 
$\gamma$-fiber texture is enhanced in the cold-rolled sheets when the HBA temperature rises from 900 to $1050{ }^{\circ} \mathrm{C}$.

Figure 9 shows the ODFs ( $\varphi_{2}=45^{\circ}$ sections) of the center layer of the final sheets with different HBA temperatures. The recrystallization textures of Sn-bearing ferritic stainless steel with different HBA temperatures are all characterized by strong $\gamma$-fiber textures with a maximum close to $\{111\}$ $<112>$. On the whole, the $\gamma$-fiber texture in the final sheets increases first and then decreases when HBA temperature increases from 900 to $1050{ }^{\circ} \mathrm{C}$, and it reaches a maximum when the HBA temperature is $950^{\circ} \mathrm{C}$. When HBA temperature increases to 1000 and $1050{ }^{\circ} \mathrm{C}$, it shows a significant reduction in recrystallization texture intensity in the final sheets. Accordingly, the exorbitant HBA temperature is not conductive to the enhancement of recrystallization texture in the final sheets.

Figure 10 shows the crystal orientation maps of the central region of the final sheets with different HBA temperatures. When the HBA temperature is $900{ }^{\circ} \mathrm{C}$, small and inhomogeneous grains are presented in the final sheets. It is apparent that the fine recrystallized grains are mainly based on the $<111>/ / \mathrm{ND}$ grains, but a number of $<001>$ // ND grains can also be observed in the final sheets. In contrast, when the HBA temperature is $950{ }^{\circ} \mathrm{C}$, the final sheets are dominated by a large amount of uniform and equiaxed $\gamma$-fiber recrystallization grains $(<111>/ / \mathrm{ND}$ grains $)$ which is favorable for improvement in the $r$ value. When the HBA temperature increases from 950 to $1000{ }^{\circ} \mathrm{C}$, the volume fraction of $<111>/ / \mathrm{ND}$ grains in the final sheets is decreased, and the grain size of $<111>/ / \mathrm{ND}$ grains is increased. When the HBA temperature increases to $1050{ }^{\circ} \mathrm{C}$, it is clearly shown that the $<111>/ / \mathrm{ND}$ grains of the final sheets decrease significantly, while the grains with other orientations are significantly increased.

In ferritic stainless steels, $\gamma$-fiber recrystallization texture is closely connected with the "oriented nucleation" and "selective growth" mechanism of $\{111\}$ recrystallization grains [20, 22, 23]. Recrystallization nucleation is largely affected by the stored energy, since it supplies a driving force for recrystallization [19]. The dislocation densities are generally heightened near the grain boundaries during deformation process, which results in an increase in the stored energy [21]. In addition, the $\{111\}$ recrystallized grains usually nucleate on the grain boundaries of the $\{111\}$ deformed grains [22, 23]. Hence, the grain boundaries provide a good condition for recrystallization nucleation. As is noted earlier, the deformation bands in cold-rolled sheets are widened and the number of grain boundaries is decreased with the increase in HBA temperature. In view of this, the stored energy and the nucleation sites for recrystallization grains are decreased with the rising HBA temperature, which will be unfavorable for the formation of $\{111\}$ recrystallized

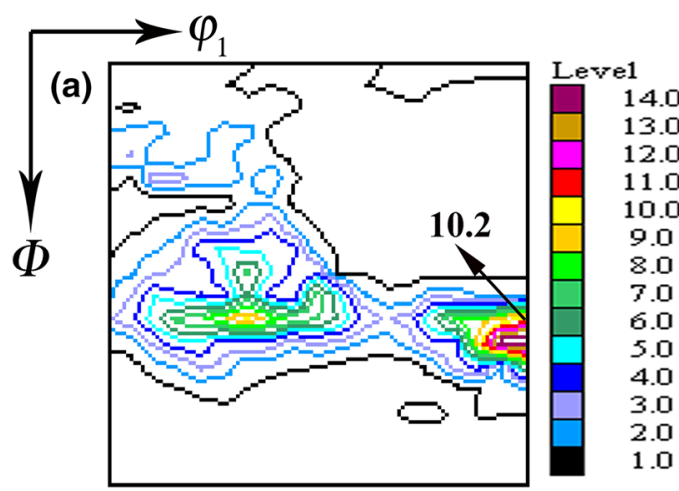

(b)

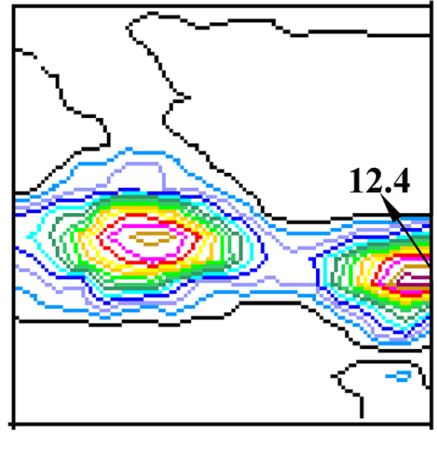

(d)

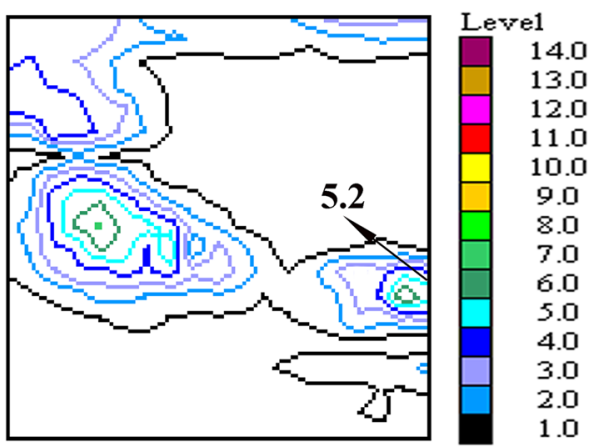

Fig. 9 ODFs $\left(\varphi_{2}=45^{\circ}\right.$ sections) of center layer of final sheets with different hot band annealing temperatures: $\mathbf{a} 900{ }^{\circ} \mathrm{C} ; \mathbf{b} 950{ }^{\circ} \mathrm{C} ; \mathbf{c} 1000{ }^{\circ} \mathrm{C} ; \mathbf{d}$ $1050{ }^{\circ} \mathrm{C}$ 

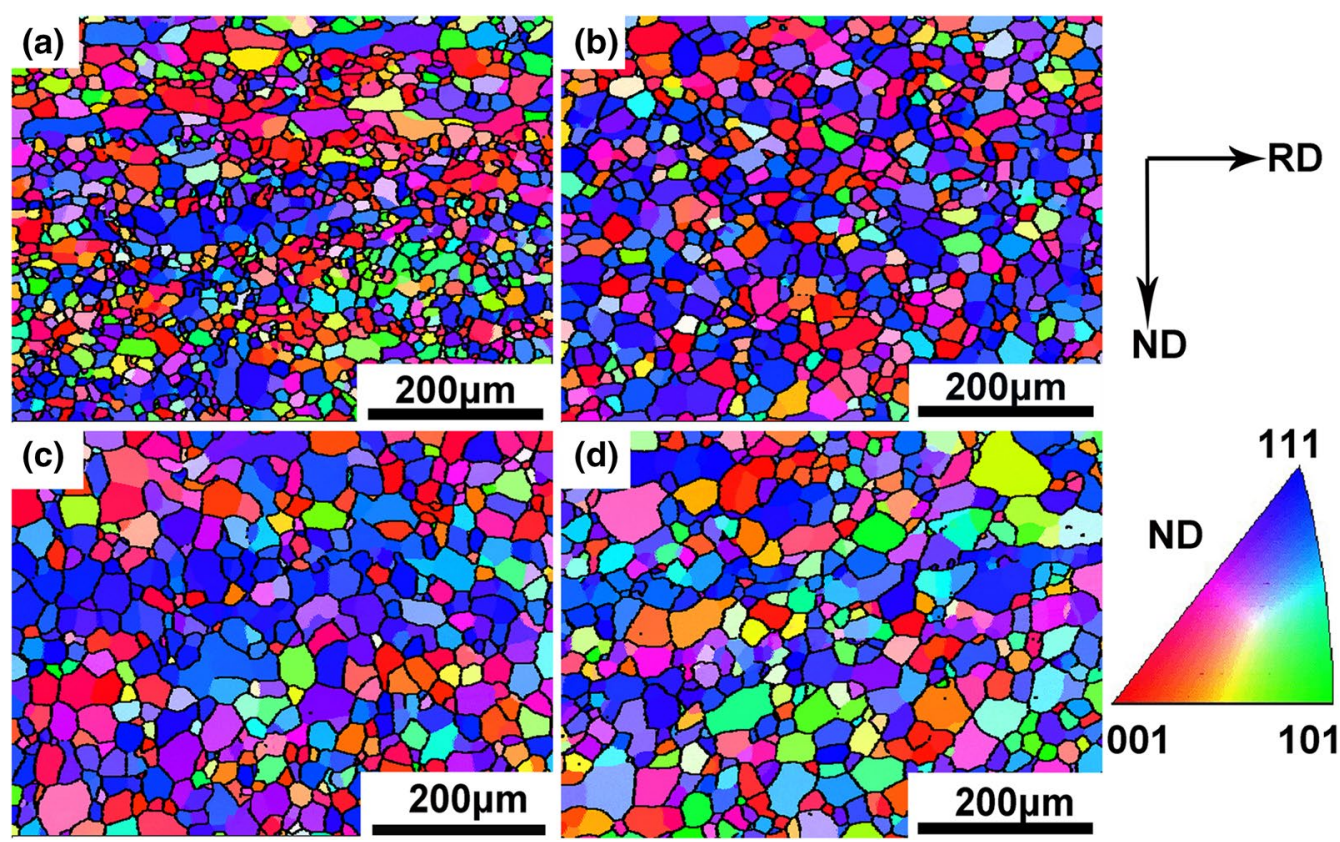

Fig. 10 Crystal orientation maps of central region of final sheets with different hot band annealing temperatures: a $900{ }^{\circ} \mathrm{C}$; b $950{ }^{\circ} \mathrm{C}$; $\mathbf{c} 1000{ }^{\circ} \mathrm{C}$; d $1050{ }^{\circ} \mathrm{C}$

nuclei. On the other hand, the $\{111\}$ recrystallized nuclei will grow up to the adjacent orientated deformed ferrite grains through the original grain boundaries during the recrystallization process. Obviously, the wider the deformation band in the cold-rolled sheets, the more difficult it is for the $\{111\}$ recrystallized grains to pass through the original grain boundaries and annex the adjacent deformed ferrite grains during recrystallization, which will not be conductive for the development of $\gamma$-fiber recrystallization texture. Hence, the $\gamma$-fiber recrystallization texture intensity in the final sheets will be greatly decreased with the increase in HBA temperature. According to our experimental result, the $\gamma$-fiber texture intensity in the final sheets increases first and then decreases with the rising HBA temperature, and it reaches a maximum when the HBA temperature is $950{ }^{\circ} \mathrm{C}$. The result can be illustrated by the crystal orientation maps of the final sheets, since the recrystallization texture is also connected with the recrystallization microstructure. As is mentioned earlier, when the HBA temperature is $900{ }^{\circ} \mathrm{C}$, small and inhomogeneous grains are presented in the hot band annealed samples (Fig. 2a), and thus, the small and uneven recrystallized grains are retained in the final sheets during the subsequent cold rolling and annealing due to the heredity of the microstructure (Fig. 10a). In comparison, more uniform and equiaxed grains are presented in the final sheets with the HBA temperature of $950{ }^{\circ} \mathrm{C}$ (Fig. 10b), and thus, the $\gamma$-fiber recrystallization texture with a high orientation density appears in it. When the HBA temperature rises to 1000 and $1050{ }^{\circ} \mathrm{C}$, the width of the deformation bands in the cold-rolled sheets greatly increases, and the number of grain boundaries greatly decreases, which will be unfavorable for the nucleation and growth for $\{111\}$ recrystallized grains, and thus, the texture intensity of final sheets is greatly decreased with the rising HBA temperature.

\subsection{Formability}

Figure 11 shows the formability for Sn-bearing ferritic stainless steel with different HBA temperatures. The average plastic strain ratio $(\bar{r})$ and earring coefficient $(\Delta r)$ are important indexes in evaluating the formability of ferritic stainless steels [24, 25], and these parameters are determined in our present study so as to assess the formability of our experimental steel. As shown in the figure, the average $r$ value increases first and then decreases with the rising HBA temperature, and it reaches a maximum of 1.71 when HBA temperature is $950{ }^{\circ} \mathrm{C}$. The formability of ferritic stainless steel is connected with recrystallization texture and microstructure [26]. As is mentioned earlier, the uniform and intensive $\gamma$-fiber recrystallization texture associated with uniform grain size distribution is beneficial to the improvement in the formability of FSSs. In our present study, the uneven $\gamma$-fiber recrystallization texture is presented in final sheets with HBA temperature of $900{ }^{\circ} \mathrm{C}$, and meanwhile, the non-uniform grains are also existed in it, which deteriorates the formability. In terms of the final sheets with HBA temperature of $950{ }^{\circ} \mathrm{C}$, the $\gamma$-fiber recrystallization texture intensity 


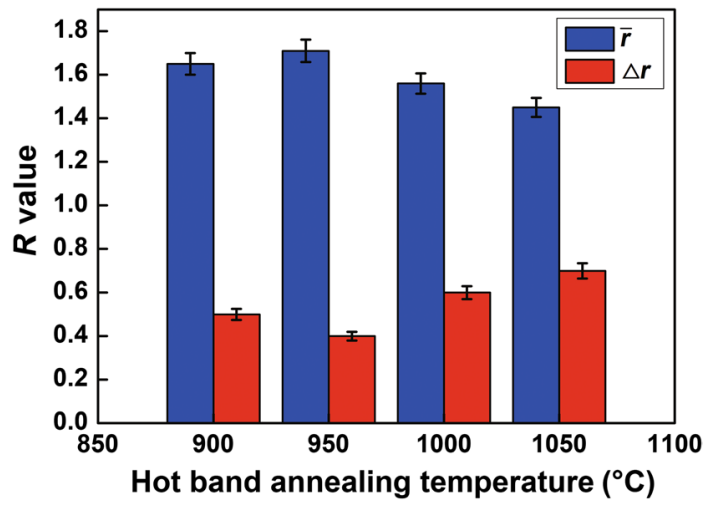

Fig. 11 Formability of Sn-bearing ferritic stainless steel with different hot band annealing temperatures

reaches a maximum with the strongest texture component located at $\{111\}<112>$, and the maximum $r$ value and the optimum formability are obtained as a result. When the HBA temperature increases to 1000 and $1050{ }^{\circ} \mathrm{C}$, the $\gamma$-fiber recrystallization texture intensity in the final sheets sharply decreases with increased HBA temperature, which is the reason why average $r$ value significantly reduces when it is at this temperature range.

The $\Delta r$ value also has a close relationship with crystallographic texture, and distinct orientations have distinct $\Delta r$ values. In body-centered cubic (bcc) metals, $\{111\}$ $<110>$ and $\{111\}<112>$ orientations have a small $\Delta r$ value, while $\{001\}<110>$ and $\{112\}<110>$ orientations possess a larger $\Delta r$ value [25]. Combining with the ODFs of the final sheets, the $\{111\}<112>$ recrystallization texture slightly increases first and then significantly decreases with the rising HBA temperature, and the texture intensity reaches a maximum when it is at $950{ }^{\circ} \mathrm{C}$. Accordingly, the $\Delta r$ value decreases first and then increases with the increase in HBA temperature, and the minimum $\Delta \mathrm{r}$ value is obtained in the final sheets with HBA temperature of $950{ }^{\circ} \mathrm{C}$.

\subsection{Ridging Resistance}

In order to explore the effect of HBA temperature on the ridging resistance of Sn-bearing ferritic stainless steel, we obtained the surface roughness profiles after $15 \%$ pre-tensile deformation of the experimental steels with different HBA temperatures which are shown in Fig. 12. The ridging height is also calculated according to the surface roughness profiles, and the ridging height of the Sn-bearing ferritic stainless steel with $\mathrm{HBA}$ temperature range from 900 to $1050{ }^{\circ} \mathrm{C}$ is 5.505, 4.688, 6.287 and $7.349 \mu \mathrm{m}$, respectively. Evidently, the ridging height of the final sheets decreases first and then increases with the increase in HBA temperature, and the minimum ridging height and the highest resistance against surface ridging are obtained when HBA temperature is $950{ }^{\circ} \mathrm{C}$.

Ridging mechanism has been investigated by many researchers so as to improve ridging resistance of the steel
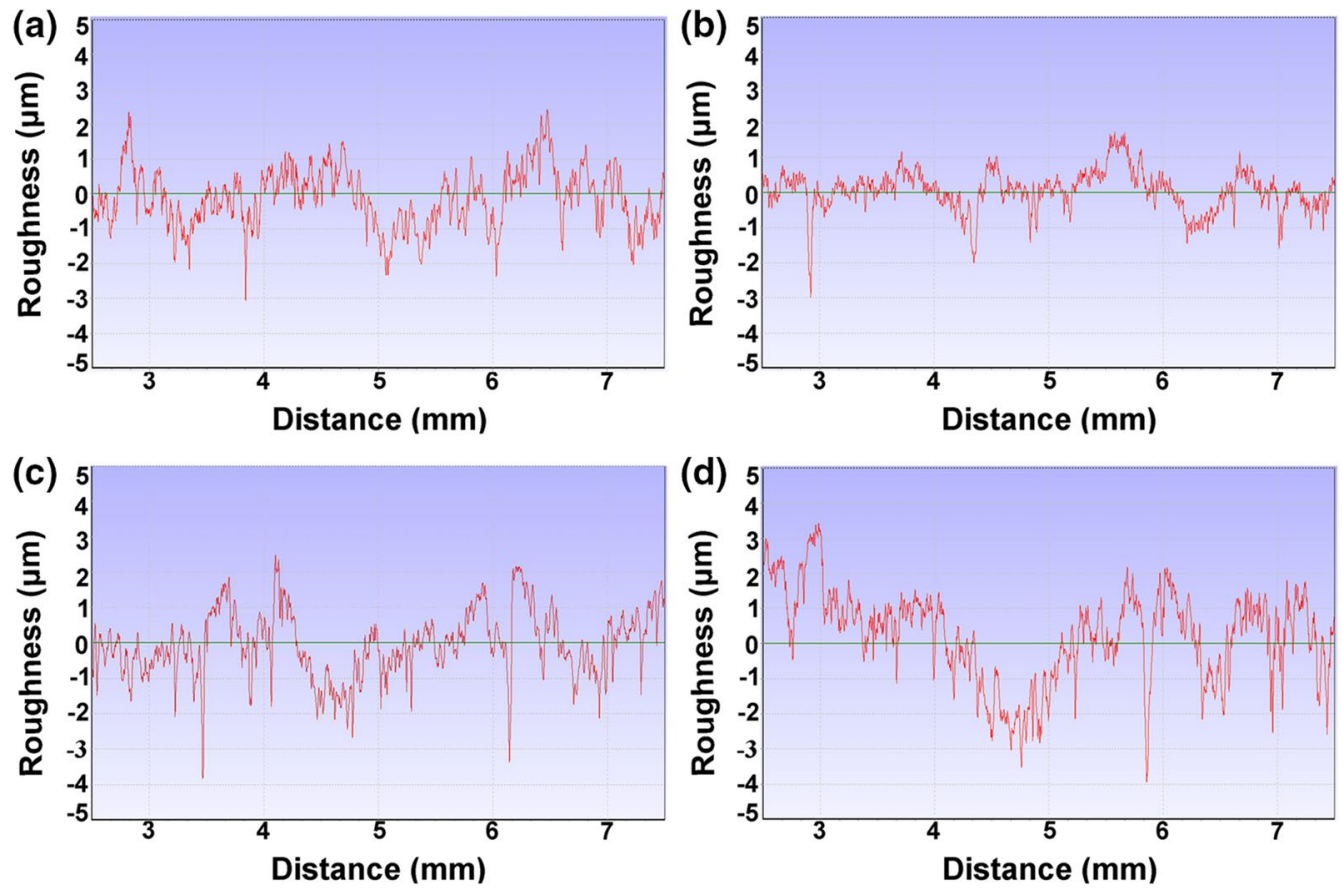

Fig. 12 Surface roughness profiles of final sheets after tensile testing strained by $15 \%$ : a $900{ }^{\circ} \mathrm{C} ; \mathbf{b} 950{ }^{\circ} \mathrm{C} ; \mathbf{c} 1000{ }^{\circ} \mathrm{C} ; \mathbf{d} 1050{ }^{\circ} \mathrm{C}$ 
sheets $[27,28]$. Currently, it is widely accepted that the surface ridging has a close relationship with the grain colonies with similar orientations [29-31]. Viana et al. [32] proposed that the different plastic behaviors of $\{001\}<u v w>$ and $\{111\}<u v w>$ grain colonies that caused severe surface ridging, and meanwhile, the inhomogeneity of microstructure also resulted in a ridging. Shin et al. [33] concluded that texture components had a great effect on ridging height in bcc metals. The $\{001\}<110>$ colonies significantly increase ridging of FSS due to a low Taylor factor [12]. In case of our present study, when HBA temperature is $900{ }^{\circ} \mathrm{C}$, inhomogeneous grains are presented in the final sheets, and a number of $<001>/ /$ ND grains can also be observed in it. In contrast, when $\mathrm{HBA}$ temperature is $950^{\circ} \mathrm{C}$, a large number of uniform and equiaxed $<111>/ / \mathrm{ND}$ grains are presented in the final sheets. Hence, a greater ridging height is obtained in the final sheets with HBA temperature of $900{ }^{\circ} \mathrm{C}$. The average grain size also has a great influence on the surface ridging of FSS. Ma et al. [12] concluded that ridges are caused by movement and rotation of grains with distinct orientations, and the ridging increases with the increasing grain size. In our present study, the ridging height of final sheets also presents an increase with the increased grain size when the HBA temperature rises from 950 to $1050{ }^{\circ} \mathrm{C}$. The key reason is that the irregularity arisen by slip and rotation of grains will be more remarkable for grains with an increasing size, and thus, a coarser grain size results in a higher ridging height.

\section{Conclusions}

(1) The microstructure, texture, formability as well as surface ridging of a Sn-bearing ferrite stainless steel under different hot band annealing temperatures were studied. Optimizing hot band annealing process is beneficial to reduce the amount of grains with $\{001\}<110>$ orientations and weaken the texture intensity, and thus, to reduce ridging and improve formability.

(2) When hot band annealing temperature ranges from 900 to $1050{ }^{\circ} \mathrm{C}$, a maximum $r$ value of 1.71 is obtained in the final sheets with hot band annealing temperature of $950{ }^{\circ} \mathrm{C}$ due to the presence of $\gamma$-fiber texture with a high intensity and uniform and equiaxed recrystallized grains.

(3) The final sheets with hot band annealing temperature of $950{ }^{\circ} \mathrm{C}$ are comprised of a large number of uniform and equiaxed $<111>/ / \mathrm{ND}$ recrystallized grains that contribute to a minimum ridging height and an optimum surface quality.
Acknowledgements This work was financially supported by the National Natural Science Foundation of China (No. U1860201) and the Fundamental Research Funds for the Central Universities (No. 162704001).

\section{References}

[1] H.X. Li, H. Yu, T. Zhou, B.L. Yin, S.J. Yin, Y.L. Zhang, Mater. Des. 84, 5 (2015)

[2] T. Kamimura, K. Kashima, K. Sugae, H. Miyuki, T. Kudo, Corros. Sci. 62, 9 (2012)

[3] X.J. Zhang, F. Gao, Z.Y. Liu, J. Iron Steel Res. Int. 23, 10 (2016)

[4] N.D. Nam, J.K. Min, Y.W. Jang, J.G. Kim, Corros. Sci. 52, 1 (2010)

[5] A. Pardo, M.C. Merino, M. Carboneras, F. Viejo, R. Arrabal, J. Munoz, Corros. Sci. 48, 5 (2006)

[6] H. Luo, C.F. Dong, K. Xiao, X.G. Li, RSC Adv. 6, 12 (2016)

[7] H. Luo, H.Z. Su, B.S. Li, G.B. Ying, Appl. Surf. Sci. 439, 1 (2018)

[8] J.I. Hamada, N. Ono, H. Inoue, ISIJ Int. 51, 10 (2011)

[9] J. Shu, H.Y. Bi, X. Li, Z. Xu, J. Mater. Process. Technol. 212, 1 (2012)

[10] H.T. Yan, H.Y. Bi, X. Li, Z. Xu, Mater. Charact. 60, 1 (2009)

[11] M.Y. Huh, O. Engler, Mater. Sci. Eng. A 308, 1-2 (2001)

[12] X.G. Ma, J.W. Zhao, W. Du, X. Zhang, L.Z. Jiang, Z.Y. Jiang, Mater. Sci. Eng. A 685, 8 (2017)

[13] J. Shu, H.Y. Bi, X. Li, Z. Xu, J. Mater. Eng. Perform. 23, 3 (2014)

[14] K.M. Lee, M.Y. Huh, S. Park, O. Engler, ISIJ Int. 52, 3 (2012)

[15] W. Du, L.Z. Jiang, Q.S. Sun, Z.Y. Liu, X. Zhang, J. Iron Steel Res. Int. 17, 7 (2010)

[16] I. Tikhovskiy, D. Raabe, F. Roters, Scr. Mater. 54, 8 (2006)

[17] X. Zhang, L.J. Fan, Y.L. Xu, J. Li, X.S. Xiao, L.Z. Jiang, Mater. Charact. 89, 5 (2016)

[18] M. Sánchez-Araiza, S. Godet, P.J. Jacques, J.J. Jonas, Acta Mater. 54, 11 (2006)

[19] K. Verbeken, L. Keatens, J.J. Jonas, Scr. Mater. 48, 10 (2003)

[20] H.T. Liu, Z.Y. Liu, Y.Q. Qiu, G.M. Cao, C.G. Li, G.D. Wang, Mater. Charact. 60, 1 (2009)

[21] O. Engler, Metall. Mater. Trans. A 30, 6 (1999)

[22] Y.Y. Tse, G.L. Liu, B.J. Duggan, Scr. Mater. 42, 1 (1999)

[23] R. Sebald, G. Gottstein, Acta Mater. 50, 6 (2002)

[24] H.T. Yan, H.Y. Bi, X. Li, Z. Xu, J. Mater. Process. Technol. 209, 5 (2009)

[25] F. Gao, F.X. Yu, R.D.K. Misra, X.J. Zhang, S.M. Zhang, Z.Y. Liu, J. Mater. Eng. Perform. 24, 10 (2015)

[26] F. Gao, Z.Y. Liu, H.T. Liu, G.D. Wang, Acta Metall. Sin. (Engl. Lett.) 24, 5 (2011)

[27] C. Zhang, Z.Y. Liu, G.D. Wang, J. Mater. Process. Technol. 211, $6(2011)$

[28] P.D. Wu, H. Jin, Y. Shi, D.J. Lloyd, Mater. Sci. Eng. A 423, 1-2 (2006)

[29] J. Mola, I. Jung, J. Park, D. Chae, B.C. De Cooman, Metall. Mater. Trans. A 43, 1 (2012)

[30] P.D. Wu, D.J. Lloyd, Y. Huang, Mater. Sci. Eng. A 427, 1-2 (2006)

[31] C. Zhang, L.W. Zhang, Z.Y. Liu, Acta Metall. Sin. (Engl. Lett.) 29, 6 (2016)

[32] C.S.C. Viana, A.L. Pinto, F.S. Candido, R.G. Matheus, Mater. Sci. Technol. 22, 3 (2006)

[33] H.J. Shin, J.K. An, S.H. Park, D.N. Lee, Acta Mater. 51, 16 (2003) 